\title{
Discussion on the Innovation of Enterprise Human Resource Performance Management in the Era of Big Data
}

\section{Yan Chen}

People's Government of Zhegou Town, Sishui County, Jining City, Shandong Province, Jining, Shandong, 273200, China

\begin{abstract}
Nowadays, the era of big data has been with the continuous development of information networks and applications quietly penetrate into every aspect of our lives, which is also officially announced that the era of big data has come. The advent of the big data era has created very favorable conditions for the development and management of enterprises. But at the same time, it has also brought them greater problems and challenges. Human resource management is a very important part of an enterprise, and it is particularly important to better achieve the level of human resource performance management and effective efficiency in the era of big data. The paper discusses the innovative direction of HRM for enterprises in the era of big data.
\end{abstract}

\section{Keywords}

the era of big data; enterprise human resources; performance management and innovation

\section{论大数据时代企业人力资源绩效管理创新}

陈琰

山东省济宁市泗水县柘沟镇人民政府, 中国・山东济宁 273200

摘 要

如今，大数据时代已经随着信息网络的不断发展和应用悄无声息的渗透我们生活的方方面面，这也正式宣告大数据时代已来 临。大数据时代的到来为企业的发展和管理营造了非常有利的条件。但与此同时，这也为他们带来了更大的难题和挑战。人 力资源管理对于企业来说是一个非常重要的部分, 更好地实现人力资源绩效管理水平和有效提高效率在当今这个大数据时代 显得尤为重要。论文针对大数据时代企业人力资源管理创新方向进行论述。

关键词

大数据时代; 企业人力资源; 绩效管理和创新

\section{1 引言}

在如今这个大数据时代, 怎样能更好地实现企业人力资 源绩效管理水平，有效地提高效率是值得思考的问题。要想 实现这一目标, 必须在不断的实践运用中寻找规律。事实上, 现在中国的人力资源管理这一领域相关制度还不太完善, 所 以导致它本身还存在着一定程度上的不足。在这种情况下， 越来越多的企业将怎样运用大数据时代的环境来更大程度地 使人力绩效管理进行创新来作为一个重大的问题进行研究。 将大数据进行有效的运用, 提高人力资源绩效管理效率, 能 让企业得到更好的发展和进步 ${ }^{[1]}$ 。论文就以这一课题为方向 进行研究探析。
2 对于企业人力资源管理来说，“大数据”有 着非常重要的作用

2.1 更好地对组织结构进行优化, 创造良好的企业 文化

人力资源绩效管理在充分对网络技术进行运用的这种基 础下不仅能对企业组织管理的资源进行共享, 还对现代企业 创建一个科学的组织框架有非常好的指导作用。这样既能营 造一个非常良好的企业文化环境，也能使企业得到更好的发 展和进步。网络技术和大数据是紧密相联的, 是互相融合、 互相促进的。除此之外, 利用互联网这一技术可以让企业的 内外部紧密联系, 使一些有效信息能得到更快的传递和共享, 这样还能让企业在运营过程中所凸显的一些管理问题得到迅 
速的解决，企业内部之间的交流也更加频繁，这为企业日后 的发展及进步奠定了良好的基础。运用网络技术和大数据的 关系，可以为企业的发展创造十分有利的条件。

通过创建科学的组织结构, 可以让企业文化得到一个更 好的发展和进步, 当企业文化达到了一个质的飞跃以后, 那 公理所当然的，企业日后的发展一定也会蒸蒸日上。良好的 企业文化对企业日后的发展是非常重要且必要的，有了良好 的企业文化可以凝聚员工们的企业向心力, 激起他们的工作 热情, 进而保障整个企业的生产率 ${ }^{[2]}$

\section{2 保证人力资源绩效考核的公平公正性、结果透明 化、公开化}

对于一个企业员工来说，不仅仅会关注自己的绩效考核 成绩，更会把注意力放在自己周围人的绩效考核上。这就要 求人力资源绩效考核在管理过程中, 一定要使考核成绩的公 平公正性得到一个好的保证，做到考核过程和考核成绩透明 化, 否则会让员工在工作过程中产生怨恨、失望心理, 工作 效率也会大大降低。这就像一个学生拿到试卷后, 不但会在 乎自己的成绩, 对于自己同学的成绩会更加注意, 当他发现 一个作弊的同学比自己的分数高并拿到了奖励之后, 那么在 之后的学习过程中他就可能无法在保证一种脚踏实地的工作 态度了。

对员工进行考核评估时, 为了避免一些人为或者主观因 素的影响, 采用大数据的方式来对员工的表现和工作效率进 行综合评估, 然后将得到的结果通过大数据展现到员工面前, 进而保证绩效评估的公平公正性，员工也能对这种结果信服。 运用大数据和网络技术来保障人力资源绩效管理过程中的公 平公正性，不但可以让员工的基本权益得到保证，而且还能 使员工对绩效考核的结果信服，从而在以后的工作中更加刻 苦努力, 促进企业的良性竞争, 进而使企业得到更好的发展 和进步。

\section{3 让员工的综合潜能得到最大程度的释放, 提高其 工作积极性}

对一个企业的发展和进步起到最大作用的就是企业员 工。即使一个企业有最好的领导人和项目, 但是如果缺少员工, 那么一切就是枉然。因此, 企业员工对企业的发展有着非常 大的作用。

在如今这个大数据的背景下, 企业的人力资源管理要尽
量让员工的最大潜能得到释放, 通过挖掘他们的潜能, 释放 他们的工作激。要想让员工释放出他们无限的能量, 人力资 源管理可以通过一些适当的手段来实现，如一些适度的奖励 和惩罚方法。当这些有效的奖惩和绩效考核紧紧联系在一起 的时候, 员工们的工作热情自然而然的就会被带动起来, 从 而工作效率和工作水平也会大大提高。通过运用大数据, 来 对员工们的工作成绩进行综合评估，这样会大大提高员工们 的工作水平, 进而提升整个企业的工作效率。就像这样利用 一些有效的规章制度和方法来激励约束员工，可以不断地去 发掘员工们的综合潜能，在让员工的自我价值得到实现的同 时，也会加快企业的发展与进步。

\section{3 在大数据背景下, 提升企业人力资源绩效管 理水平的途径}

\section{1 对绩效管理数据和评估内容进行拓展}

数据的管理在如今企业的管理过程中是非常重要且关键 的一部分, 而数据管理中占有很大比重的莫过于人力资源绩 效管理。当企业想要对员工的工作情况进行更好的掌握和了 解时, 往往都是通过根据相关考核员工所建立的, 将有关他 们的相关信息建立一个数据库, 这些数据库会根据员工的变 更情况来进行实时的更正与更新。而这些都运用了人力绩效 管理的数据管理。企业的管理层想对员工信息进行了解时, 也可以通过这些实时更新的数据库, 通过数据库所反映出来 的员工信息，管理层人员可以对员工的工作内容来进行更好 的安排和管理, 十分方便快捷并且还非常的准确化。

通过这种手段，能加强企业的人力资源管理，使企业管 理更加科学化、标准化, 促进企业的发展与进步。除此之外, 通过人力资源管理中的数据管理让数据库与其他相关设备相 连接, 让管理者对员工的出勤、工作表现、工作效率进行全 面的了解和掌握，从而使之后的人力资源绩效考核的内容得 到更好的拓展，使绩效考核更加公平、公正 ${ }^{[3]}$ 。

\section{2 制定科学有效的绩效考核管理制度}

企业要想对员工的工作能力深入了解，就要对人力资源 的绩效管理进行强化。通过不同员工的不同职责和不同的工 作特点来为他们切身定制一个具有针对性的考核管理制度。 例如，在对公司里的销售员工的绩效进行考核时，更加看重 的应该是他们的工作效率和客户对这名销售人员的满意程度。 但是对于一些文职人员来说，考核方法肯定就得因人而异， 
需要更变, 更加看重的应该是他们对待工作时的态度等 ${ }^{[4]}$ 。 因此, 要想让一个企业的人力资源绩效考核管理得到长远发 展, 企业就要根据自己的实际情况和员工们的工作特点来制 定一个切实有效并且具有针对性的考核管理制度。通过较科 学的考核方式, 让人力资源绩效管理得到更大的发展和进步。 在大数据的时代背景下, 如果我们能运用好网络技术和大数 据的关系，就会让企业的人力资源绩效考核制度更加完善和 完备，也能让企业得到更好的发展和进步。

\section{4 结语}

综上所述，论文首先介绍了大数据在企业人力资源绩效 管理中的作用，对运用大数据的方法提升人力资源绩效管理 水平提出了建议。对于当前的企业人力资源绩效管理来说, 制度不是太完善, 还存在着很多问题。如果借助网络技术和 大数据之间的关系，就会很好地促进人力资源绩效管理制度 的完善，从而让企业得到更好的发展和进步。然后介绍了科
学的管理制度，以提高员工的工作效率和工作水平，促进企 业里的良性公平竞争，进而促进企业的发展和进步。最后论 文介绍了如何运用大数据创新人力资源绩效考核制度，对不 同类型的员工进行有针对性的考核制度，间接地促进企业的 顺利发展。

\section{参考文献}

[1] 杨晶晶. 互联网时代下传统企业人力资源管理模式转型研究 [D] 武汉 : 湖北工业大学,2017.

[2] 金艳. 探究大数据时代企业人力资源绩效管理创新 [J]. 大众投资 指南, 2019(01):88.

[3] 钟文浩, 陈胜军.大数据时代下企业人力资源绩效管理创新发展 的途径 [J]. 中国商论, 2020(06):23-24.

[4] 贺亮. 大数据时代环境企业人力资源绩效管理创新策略探究 [J]. 现代企业文化, 2018(32):360. 